\title{
Paris Agreement Agreement 2015 and its Impact on Indonesian National Law
}

\author{
Andreas Pramudianto ${ }^{1}$ \\ \{uipram@gmail.com ${ }^{1}$ \} \\ School of Environmental Science, University of Indonesia
}

\begin{abstract}
The 2015 Paris Agreement (PA 2015) was agreed in December 2015. This agreement indicates that the issue of climate change will remain a global agenda at least until 2030. The 2015 Paris Agreement position will replace the 1997 Kyoto Protocol as one of the climate change agreement regime (UNFCCC 1992). Indonesia has participated and signed and ratified the 2015 Paris Agreement. By ratifying the international law into national law through the Law No. 16 of 2016, it will have an impact on the existence of Indonesian national law. The purpose of this study is to examine the relationship between international law in the form of the 2015 Paris Agreement and Indonesia's readiness through national law as an implementation at the national levels. The results of the study show that some national legislation has been adjusted to the 1992 UNFCCC, 1997 Kyoto Protocol and 2015 Paris Agreement objectives. The conclusions of this study indicate that there are significant impacts of the existence of international agreements on national legal instruments. This research has also shown that Indonesia has committed to implement the 2015 Paris Agreement with the legislation as a measure of the successful implementation of international agreements.
\end{abstract}

Keywords: Paris Agreement 2015; National Law; NDC; International Agreements, Legislation Products.

\section{Introduction}

Climate change has become a global environmental agenda. Climate change occurs due to an increase in human activity on the use of fossil fuel so as to produce high greenhouse gas emissions. The impact of climate change has been felt in almost all sectors of life. Real action is needed to deal with the impacts of climate change through adaptation and mitigation efforts. One important tool in achieving global commitments to reduce greenhouse gas emissions is a global agreement through international agreements. UNFCCC in 1992 was agreed upon with the aim of stabilizing greenhouse gases to efforts to reduce emissions through the 1997 Kyoto Protocol which is valid until 2020. In the year after 2020 a new, more binding and ambitious agreement is needed. After lengthy negotiations, on December 12nd in year 2015 the 2015 Paris Agreement was agreed which aims to replace the 1997 Kyoto Protocol and attempt to reduce greenhouse gas emissions by 2030 [1]. The 2015 Paris Agreement is a more state's participatory in International Agreement since almost all countries have obligation to reduce greenhouse gas emissions measured through National Determined Contribution (NDC) [2]. Indonesia has been fully involved in the negotiation process until an agreement is reached through the signing of an international agreement instrument namely the Paris Agreement in 2015. A year later Indonesia ratifies the 2015 Paris Agreement to become national law. This 
will certainly have an impact on the existence of national law that has existed so far. Various instruments of national legislation both the Law, Government Regulations, Presidential Regulations until the regulations below will adjust to the provisions of the Paris Agreement 2015. On the other hand the policy of the central government must also be followed by the local government through a local law instrument such as the Regional Regulation up to Village Regulation. But for this adjustment it takes time and process that is long enough to be able to adjust to the 2015 Paris Agreement.

\section{Theory and Literatur Review}

Mitchell said that there were more than 1,000 international agreements in the field of environment both multilateral and bilateral which were successfully formed and approved [3]. The instrument of international agreement is an agreement between countries. However, in practice in the field of international environmental law an international agreement does not only bind the subject of international law such as the state or international organizations. In certain cases, Non Governmental Organizations (NGOs) have the same attachment to other subject of international law [4]. International agreements have various forms including those in the form of international conventions, protocols, agreements and other forms. In addition there are principles of international law in dealing with climate change impacts such as bona fide, pacta sunt servanda, common but differentiated responsibility, applicable for all, as a concern for climate change regime that countries agree to sign the United Nations Convention on Climate Change (UNFCCC) on June 5, 1992. Five years later to implement the 1992 UNFCCC through its Greenhouse Gas emission reduction targets, the Kyoto Protocol was agreed in December 1997 [5] This protocol was then implemented through two periods of Commitment namely the Commitment I Period carried out in 2008 to 2013 and the Commitment II Period carried out in 2013 to 2018 which was later extended to 2020. To replace the 1997 Kyoto Protocol, through the Durban Platform was agreed to discuss an international agreement which finally agreed in 2015 namely the Paris Agreement 2015. The 2015 Paris Agreement will begin in 2020 until 2030. The provisions in the 2015 Paris Agreement regulate such as an agreement to reduce emissions below 2 degrees, reduce emissions through adaptation and mitigation, NDC, use various market mechanisms, climate finance etc. Indonesia as one of the countries that has ratified and it is necessary to implement it at the national level. UNEP (2007) asserts that institutional arrangements and mechanisms are needed to support the implementation of international agreements both at the international and national levels [5]. In Indonesia legislation products that can be issued in the form of laws (UU), government regulations (PP), Decree / Presidential Regulation (Perpres), Decree / Ministerial Regulation (Permen) and Regional Regulation (Perda). In addition, it can also be in the form of a Decree / Director General Regulation, Circular Regulation (SE), Joint Decree (SKB), Decree / Regulation of the Governor, Mayor or Regent. In integrating the provisions of international law into national law, various methods are needed in the framework of the legislative theory. 


\section{Research Methods}

This research is based on a qualitative analysis approach with quantitative combinations (mix methods). This research is desk study research and library study. Data collection is carried out based on primary and secondary data. Primary data in the form of legislation while secondary data in the form of literature. The data is carried out through the process of identification, data sorting, data usage and data analysis as well as conclusions based on research objectives.

\section{Results and Discussion}

Before the ratification of the 2015 Paris Agreement, Indonesia also ratified the 1992 UNFCCC and the 1997 Kyoto Protocol. Several implementing regulations issued before the 2015 Paris Agreement ratification compared to after the Paris Agreement ratification can be seen in the table below:

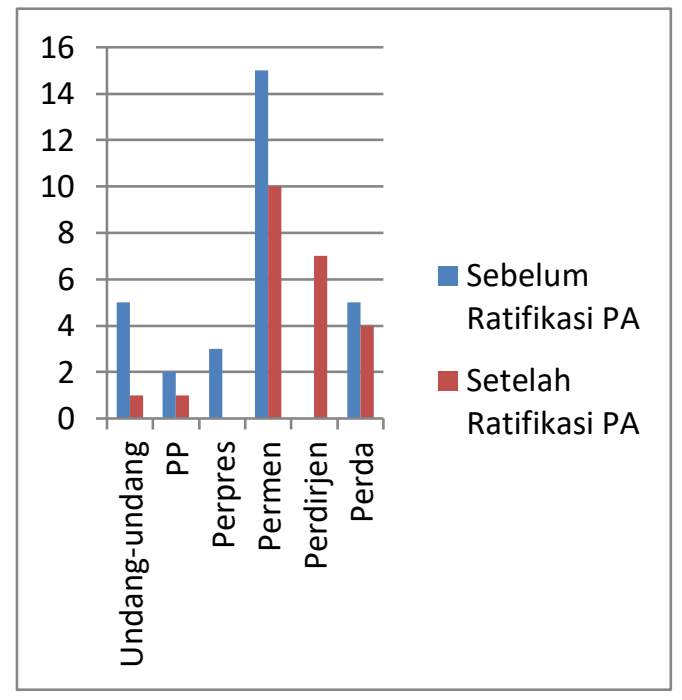

Fig. 1. Legislation issued before and after the 2015 PA ratification.

From the picture above, the legislation product acts as a follow up to the ratification of both the 1992 UNFCCC ratification, the ratification of the 1997 Kyoto Protocol and after the ratification of Paris Agreement in the form of a Ministerial Regulation is most populer. When viewed from the sector policy, the Ministry or institution that provides the most legislation products is the Ministry of Environment and Forestry (Fig. 2). 


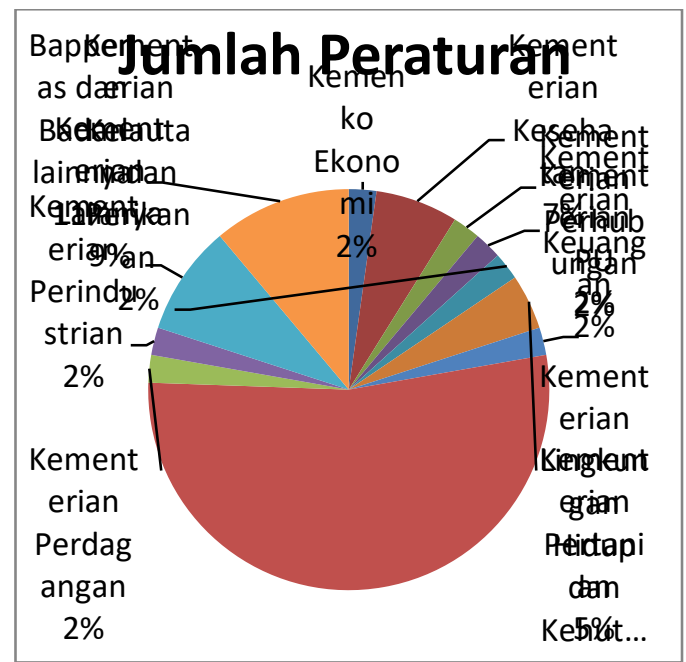

Fig. 2. Percentage of Product Regulations issued by the Ministry related to climate change.

From the data above, it appears that the number of legal products issued by the Ministry of Environment and Forestry is the most. This is in accordance with the main tasks and functions. But it should be noted that before the National Council on Climate Change (DNPI) was dissolved, the main tasks and functions of national climate change were under the DNPI.

With Indonesia's involvement and its commitment to addressing global climate change, it turns out that it has an impact on national law, especially in the legislation products have been published. National legislation has been published with a variety of purposes and objectives. When the 1992 UNFCCC was ratified by law, there are many regulation has adjusted and made such as the Minister of Health Regulation No. 035 of 2012 concerning Guidelines for Identifying Health Risk Factors Due to Climate Change. When Kyoto 1997 Protocol was ratified, adjustments were also made to national legal instruments such as Presidential Regulation Number 61 of 2011 concerning National Action Plans for Decreasing Greenhouse Gas Reductions. The 2015 Paris Agreement, although it is not yet valid globally, it requires readiness especially for national legal instruments so that the 2015 Paris Agreement can be achieved in 2030. For Indonesia it is necessary to change the provisions in its legal products, especially in the existing laws and regulations. For example, Presidential Regulation Number 61 of 2011 seems to have to accommodate new developments, especially in the framework of reducing emissions below 2 degrees and as stated in the new Indonesian NDC. Likewise, the establishment of new regulations that are urgent is mainly related to readiness to adjust to Indonesia's emission reduction commitments as stated in the Indonesian NDC. In the future, national legal instruments must also be prepared as in the face of carbon trading mechanisms that will change from the Kyoto Protocol 1997 regime to the 2015 Paris Agreement regime. Mechanisms that are calculated and recognized in the Kyoto Protocol 1997 such as Clean Development Mechanism (CDM), Joint Implementation (JI) and Emission Trading (ET), will develop in the 2015 Paris Agreement through a non-Kyoto Protocol mechanism such as REDD plus and other mechanisms. So it is necessary to develop Measurement, Registration and Verification (MRV) that can be recognized and taken into account in reducing emissions. For that national law products must be prepared and able to follow new developments so that 
by 2020, Indonesia will be ready to implement the 2015 Paris Agreement as a global commitment.

International law has a very important impact on national legal instruments, especially in increasing the capacity of national law itself. The rules are not yet valid, then because of an increase in global commitments in the framework of reducing emissions, national commitments must be increased. In addition, national and regional institutions must also be formed to be able to adjust to the provisions of the 2015 Paris Agreement. Required funding is available or utilizing international funds provided in the 2015 Paris Agreement framework. On the other hand the use of low-carbon technology will affect technological development in Indonesia is expected to be in accordance with the 2015 Paris Agreement commitment. The important thing of the 2015 Paris Agreement as an international legal instrument, of course, will increase the knowledge, understanding and awareness of the Indonesian people in order to be transformed towards improving national environmental quality and also in accordance with the commitment Sustainable Development Goals (SDGs) in line with the 2015 Paris Agreement.

\section{Conclusion and Recommendation}

The conclusions of this study are:

a. The 2015 Paris Agreement is a global commitment that must be implemented by Indonesia through an adequate legal instrument.

b. The national legal instruments include products of national legislation that some have been able to adjust to readiness towards the implementation of the 2015 Paris Agreement.

c. An important impact on national law is that there is an increase in legal capacity, institutions, funding, technology and human resources that can be included in the provisions of national legislation,

d. Adjustment to legislation products so that they are in line with the 2015 Paris Agreement objectives will increase national development capacity to be in line with the Sustainable Development Goals (SDG).

e. The existence of NDC is a benchmark in the process of forming future legislation.

While the recommendations are the need for a more in-depth study, especially in the ability to make decisions related to the provisions of the 2015 Paris Agreement that must be adapted to national law products.

\section{References}

[1] Robert Falkner. The Paris Agreement and the New Logic of International Climate Politics, 92 International Affair 1107 (2016).

[2] Paris Agreement-Status of Ratification. UN Framework Convention on Climate Change. http://unfccc.int/paris_agreement/

[3] Ronald B Mitchell. November 2003. Annual Review of Environment and Resources $28 \quad(1) \quad$ : 429 - 61 DOI: 10.1146 /annurev .energy .28.050302 dalam https://www.researchgate.net/publication/228544665_International_environmental_agreements_A_su rvey_of_their_features_formation_and_effects

[4] Phillipe Sands. Principle of International Environmental Law, Cambridge University Press (1995). 
[5] UNEP. 2007. Negotiating And Implementing Multilateral Environmental Agreements (MEAs): A Manual For NGOs. UNEP- Earth Media-CEDEA Stakeholders Forum. 